\title{
INHALED FOREIGN BODIES IN A SERIES OF SUDANESE CASES
}

\author{
BY \\ W. A. L. MAcGOWAN* \\ From the University, Khartoum, Sudan
}

(RECEIVED FOR PUBLICATION JANUARY 13, 1959)

In England and Wales during 1954, 11 deaths were recorded from the inhalation of foreign bodies. The importance of such accidents in the Sudan has been demonstrated by the Thoracic Surgical Unit of Khartoum Civil Hospital since its establishment in February, 1957. The removal of inhaled foreign bodies has been the commonest emergency procedure undertaken by the Unit, and 14 patients with this condition were admitted for treatment in the Unit's first 12 months of operation. The condition is common in the Sudan owing to the large numbers of nuts and seeds eaten in the average daily diet, and peanuts and melon seeds accounted for eight of these cases (Table I). Children are especially prone to inhalation accidents and in this series were more commonly affected than adults (Table II).

TABLE I

FOREIGN BODIES INHALED

\begin{tabular}{|c|c|c|c|}
\hline \multicolumn{3}{|c|}{ Type of Foreign Body } & Number of Cases \\
\hline $\begin{array}{lll}\begin{array}{l}\text { Peanuts } \\
\text { Melon seeds }\end{array} & \ldots & \ldots \\
\text { Mud, pebble, } & \text { and stones } \\
\text { Date stone } & . & \ldots \\
\text { Metallic } & \ldots & . . \\
\text { Burr or grassheads } & \text { (haskanit } \\
\text { Meat or fish } & . . & \ldots\end{array}$ & $\begin{array}{l}\cdots \\
\cdots \\
\cdots \\
i \dagger) \\
\cdots\end{array}$ & $\begin{array}{l}\ldots \\
\cdots \\
\cdots \\
\cdots \\
\cdots \\
\cdots\end{array}$ & $\begin{array}{l}4 \\
4 \\
2 \\
1 \\
1 \\
1 \\
1\end{array}$ \\
\hline Total & $\ldots$ & .. & 14 \\
\hline
\end{tabular}

Mechanism of INHALATION

Inhalation of foreign material in the unconscious, drugged, or bedridden patient is a well-known hazard, but it is not proposed to deal with this aspect of the subject. In the conscious individual, provided the protective mechanism is intact, the accident is rare. The cough reflex is the protective mechanism that guards the larynx and that comes into play whenever extraneous foreign material touches it. A violent cough follows in an effort to expel the intruding foreign

*Present address: St. Laurence's Hospital, Dublin. body. There is, however, a defect in this reflex, namely the deep inspiration that precedes the cough and during which the larynx opens wide. A suitably placed and shaped foreign body can slip through the larynx during this phase of inspiration.

Children are frequent victims owing to their habit of swallowing nuts whole instead of chewing them. In the child, moreover, the cough reflex is less efficient and the larynx relatively larger than in the adult.

\section{Position OF ForeIgn Body}

The size and shape of the foreign body determine its position. Objects that are too large to enter the lower respiratory tract are coughed out, swallowed, or remain impacted in the larynx (Cases 9 and 14). Of those that are small enough to pass through the larynx, some fall into the trachea and lie just below the cords or near the carina. This type can be seen at endoscopy to move up and down the trachea with the movements of respiration. Others descend into the main bronchi, entering more commonly the right bronchus owing to its obliquity and larger lumen. A few may even reach the segmental branches. In this series two foreign bodies were in the larynx, five in the trachea, four in the right bronchial tree, and three in the left bronchial tree.

\section{The EFfect}

The effect of a foreign body in the respiratory passages depends not only on its position, but upon its nature, the degree of obstruction produced, and the length of time it has been present.

The composition of a foreign body also determines its effect. Peanuts and beans are irritant and set up laryngo-tracheo-bronchitis shortly after inhalation. The fatty acids in peanuts are believed to be the irritant responsible. The inflammation is clearly seen at bronchoscopy, the 
TABLE II

SUMMARY OF CASES

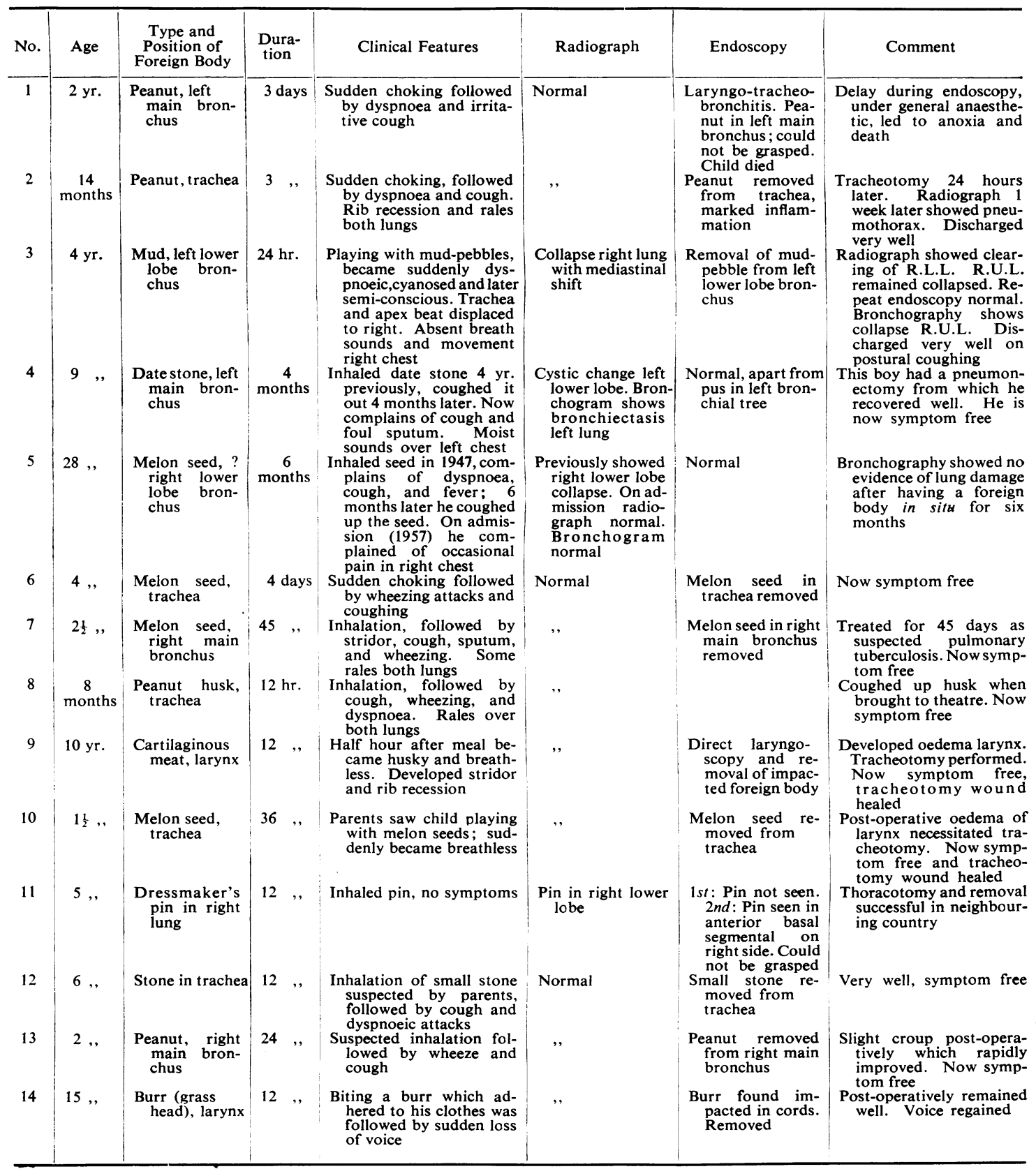


respiratory mucosa being congested, swollen, and covered with an inflammatory exudate. The swelling of the laryngeal mucosa causes resistance to the passage of the bronchos:ope, and the resulting trauma leads to further oedema. The danger of post-endoscopic laryngeal obstruction is thus considerable, particularly in infants. If the peanut is not removed then laryngo-tracheobronchitis is a common and often fatal sequel. In Clerf's (1940) series there were 12 deaths from laryngo-tracheo-bronchitis, even after removal of the foreign body.

Melon seeds, date stones, mud, and stones are relatively innocuous and cause little immediate inflammatory change. Most vegetable foreign bodies absorb moisture and swell, thus increasing obstruction. Metallic foreign bodies do not at first irritate, but some oxidize and set up inflammation later on. Pointed subjects may perforate surrounding structures.

If a foreign body lodges in the larynx and completely obstructs the airway, then asphyxia and death follow rapidly. Fortunately, partial obstruction is more common, resulting in loss of voice and a varying degree of respiratory distres 3 (Cases 9 and 14). If the foreign body is nct removed then infection and oedema of the larynx follow and, untreated, lead eventually to complete obstruction. If the foreign body slips through the larynx, it is not likely to cause complete obstruction in the trachea. Incomplete obstruction is common and respiratory distress follows. The foreign body tends to move up and down the trachea from the carina to the undersurface of the cords. The larynx is thus from time to time obstructed from below. This is the explanation of the paroxysmal attacks of acute dyspnoea. Sauerbruch and O'Shaughnessy (1937) advocated inverting the patient in an attempt to remove the foreign body. This is extremely dangerous as it can cause the foreign body to move upwards and completely obstruct the larynx with a fatal result. The erect position is the safest before endoscopy.

A foreign body can lie transversely at the carina obstructing both bronchi and occasionally causing asphyxia. The foreign body may move to this position during endoscopy, when it should be immediately displaced to one or the other side, allowing air to enter at least one lung. In the bronchus the foreign body causes obstruction of varying degrees. Collapse of whole or part of a lung is common. If the foreign body acts as a ball valve, obstructive emphysema may develop. Infection usually supervenes if the foreign body is not removed and a protracted stay can lead to pneumonitis, bronchial abscess, bronchiectasis, or empyema.

The longer a foreign body stays in the lung the greater the risk of permanent damage. Such damage, according to Sauerbruch and O'Shaughnessy, is invariable after a few weeks' lodgement, even if the foreign body is then removed. That this is not always true is well recognized and is confirmed by our experience in this series. A boy (Case 4) inhaled a date stone and retained it for four months before coughing it out. Within four years, when first seen, he had developed severe bronchiectasis. A man, on the other hand, (Case 5), inhaled a melon seed and after six months coughed it out, yet bronchography 10 years after the accident showed no lung damage. The difference in the end-result in these two cases is probably due to variation in the amount of obstruction produced by the foreign body rather than to the length of stay.

\section{Diagnosis}

The most important diagnostic point in the history is the account given by an eye-witness of the accident. In almost all cases they will state that the child was playing with, or eating one of, the well-known foreign bodies and that he choked, or became suddenly breathless. In most cases this is followed by an irritative cough, wheezing, and attacks of breathlessness. This story from a reliable witness is practically diagnostic of a foreign body in the respiratory passages. With adults the patient will usually give a similar history, though often they are not believed. Many cases are recorded where the patient's story was only found to be true when bronchoscopy was later performed for "bronchial carcinoma." The symptoms vary with the site of the foreign body ; laryngeal foreign bodies, for instance, often cause pain and loss of voice.

Stridor, cyanosis, varying degrees of dyspnoea, tracheal deviation, rib recession are the commonest signs present. These and chest signs can be misleading and reliance should not be placed upon them in making the diagnosis. Not uncommonly there are no abnormal physical signs, but here again the history will usually lead to the correct diagnosis.

A chest radiograph may or may not show changes; with a metallic foreign body it is invaluable and helps in localization. Most of the non-metallic foreign bodies cannot be seen on a chest film. Sometimes a faint shadow is observed but can easily be confused with one of the 
common hilar opacities. If the foreign body is intrabronchial, the radiograph will usually reveal secondary changes - lobar collapse, obstructive emphysema, compensatory emphysema, or mediastinal shift.

If a foreign body is swallowed and becomes impacted in the oesophagus, it may press on the trachea or bronchi and cause respiratory embarrassment. The diagnosis may then be obscure before endoscopy.

It is important to stress that with vegetable foreign bodies there may be neither abnormal physical signs nor changes in the chest film. In this series nine cases had normal radiographs and no significant physical signs on examination. In these patients the history was relied upon and found to be correct in all.

\section{TREATMENT}

Three patients (Cases 4, 5, and 8) coughed up the foreign body spontaneously, one shortly after inhalation and the other two some months later. In all the others early endoscopy was performed. Eleven children, ranging from 8 months to 10 years of age, were either bronchoscoped or laryngoscoped under a general anaesthetic. Although a local anaesthetic may be suitable for adults, a general anaesthetic is essential for children. We have found a combination of ethyl chloride and ether satisfactory. In addition, the larynx is sprayed and the trachea injected with $4 \%$ lignocaine.

In this procedure it is important to have the proper equipment. Suckling, infant, child, small and large adult-size bronchoscopes are essential. Equally important are properly fitting foreignbody forceps and suction pieces. The equipment should all be checked before use, as time should not be wasted on adjustments once the anaesthetic has begun. Up to 6 months of age the suckling bronchoscope is the most suitable size. After that age the infant size will be found satisfactory. In older children the child size is used. Do not attempt to force too large a bronchoscope through an infant's larynx. This will result in severe laryngeal oedema.

The child is then bronchoscoped and the foreign body located and grasped. If possible the foreign body is removed through the bronchoscope. Usually, however, it is necessary to withdraw forceps and bronchoscope together, a procedure that we have found satisfactory. If the foreign body is friable, it is crushed and withdrawn in pieces, residual matter being sucked out.
If the bronchoscope has been withdrawn, we re-introduce it to make certain all the foreign material has been removed. If this practice is not followed, a small piece can easily be left behind. In one patient only in this series could the foreign body not be grasped. This patient (Case 11) was a boy aged 5 years, who inhaled a dressmaker's pin. The pin was found on radiographs to lie in the anterior segment of the right lower lobe. At endoscopy the pin was not seen despite careful search. One week later the search was resumed; the radiograph then showed some movement of the pin distally. The pin's point was visible inside the anterior basal segmental bronchus. Several attempts were made to grasp the barely visible point without success. The procedure was abandoned and thoracotomy advised. It was felt that there was danger in leaving a sharp, pointed foreign body in situ in a young person. The advice was followed, though in a neighbouring country, where the pin was removed successfully. The child is now symptomfree. Robinson and Mushin (1956) had a similar case in their series that required a thoracotomy. However, though the pin could be felt in the lung, it could not be found at bronchotomy and was worked out through the visceral pleura and removed in this way.

If difficulties are encountered during endoscopy then the procedure should not be prolonged unduly (Case 1). We confine ourselves, if at all possible, to two bronchoscopies and avoid prolonged instrumentation. In this way the trauma to the larynx is reduced to a minimum. If the foreign body has not been removed, we return the patient to the ward, administer antibiotics and wait one week before trying again. If an irritating foreign body such as a peanut cannot be removed, then an immediate tracheotomy should be performed. If this is not done, the child will almost certainly die of laryngo-tracheo-bronchitis before further attempts at removal can be made. Endoscopy may be performed subsequently through the tracheostomy without difficulty. We were fortunate in that the peanuts we encountered were all relatively easy to remove. We keep our patients in the theatre until normal respiration has been resumed. If we are satisfied with the laryngeal aperture, then the child is returned to the ward where it is carefully watched. Penicillin is administered to combat infection. We found that steam tents were of no value in the hot climate of the Sudan.

Special care should be taken after bronchoscopy in children under 2 years of age, who are 
particularly liable to develop oedema of the larynx. The two children bronchoscoped under 2 years of age (Cases 2 and 10) both required a tracheotomy in the early post-operative period. The oedema usually becomes apparent within 24 hours and consequently admission to hospital and careful observation are essential.

The decision to perform a tracheotomy is a difficult one, and if left until the need is obvious it is almost always too late. It is our practice to perform a tracheotomy without delay if there are signs of increasing respiratory distress, an inspiratory and expiratory stridor, and rib recession. If there is any doubt about the decision, we perform a tracheotomy.

The third patient (Case 9) requiring tracheotomy was a child of 10 years who had a laryngeal foreign body impacted for 12 hours with laryngeal infection and oedema. Although the foreign body was easily removed, acute respiratory obstruction developed about 24 hours later and a tracheotomy had to be done.

The care of these patients after tracheotomy is important, particularly in the infant group. The tracheotomy tube can become blocked so must be cleaned regularly. A small rubber catheter should be passed frequently and suction applied. If the child is not given this attention. then a fatality may easily occur at this stage from a blocked tracheotomy tube or accumulated secretions in the respiratory passages. In Clerf's (1940) series 12 patients who had undergone trachetomy after endoscopy died. We remove the tracheotomy tube when the larynx has recovered, and this may take up to three weeks. The tube is removed in the theatre and the child watched. If stridor reappears we re-introduce the tube. The wound heals rapidly after removal of the tube, with little scarring.

The normal case is radiographed after a few days. If the chest film is satisfactory, the patient is discharged and followed up as out-patient.

\section{RESUltS}

We had one death, the first in the series (Case 1). This child had inhaled a peanut three days previously and had laryngo-tracheo-bronchitis. At bronchoscopy, under a general anaesthetic, the foreign body was seen in the left main bronchus, but before it could be grasped the child developed convulsions and cardiac arrest. In spite of cardiac massage and inflation with oxygen the child died. It was felt that in this case the interval between identifying the peanut and grasping it was unnecessarily prolonged, due to lack of suitable equipment. Anoxia ensued with a fatal result. Since this fatality we have checked all equipment necessary before induction of anaesthesia and carry out the procedure as quickly as possible.

Three patients required tracheotomy after endoscopy (Cases 2, 9, and 10). Three patients (Cases 4, 5, and 8) coughed out the foreign body, two after an interval of some months and one just before endoscopy. In two patients (Cases 9 and 14), the foreign body was removed from the larynx by direct laryngoscopy. The remainder were bronchoscoped. All these patients were well when seen some months later.

In two patients bronchoscopy and bronchography were performed some years after the inhalation episode. These and two others with features of particular interest will be described in greater detail.

CASE 2.-A child of 14 months was admitted with a history of suddenly choking while playing with peanuts three days before. The child had an irritative cough and attacks of breathlessness. On examination its colour was normal and the trachea central, but there was rib recession and rales over both lungs. A chest film was normal. Inhaled foreign body was diagnosed and the child bronchoscoped under a general anaesthetic. There was considerable inflammatory swelling of the larynx and trachea. A peanut was seen in the trachea and removed. The bronchoscope was re-introduced and no residual foreign body could be seen. Next morning the child was distressed, with stridor and rib recession. A tracheotomy was performed immediately under a local anaesthetic. Immediate relief was obtained and the child continued well on the usual post-operative regime. Some days later the patient was radiographed and to our surprise a large right pneumothorax was demonstrated. The air was withdrawn and complete re-expansion obtained. The tracheotomy tube was removed after three weeks; the child remained well. She was discharged shortly after this with a normal chest film.

This case illustrates the typical history, the sparsity of physical signs, and the normal preoperative film. The peanut had caused the usual inflammatory changes in the respiratory tract and post-operatively tracheotomy became necessary. The explanation of the pneumothorax is probably the rupture of an emphysematous bulla. Holinger and Rigby (1946) state that bullae can form beneath the visceral pleura and rupture as a result of obstructive emphysema. Presumably with the prolonged respiratory obstruction in this patient, obstructive emphysema developed, with bullae, and rupture occurred.

CASE 3.-A girl aged 4 years was admitted to hospital with a 24-hour history of inhaling a foreign body. The parents stated that on the previous day 
she had been eating mud and suddenly choked. She became extremely breathless and semiconscious. On examination she was very distressed and her breathing laboured. The trachea was deviated to the right and cardiac pulsation felt to the right of the sternum. There was no movement of the right side of the chest and breath sounds were absent over the right lung. A chest radiograph showed complete collapse of the right lung with a mediastinal shift. Radioopaque material could be seen in the ascending colon. This was assumed to be mud and a diagnosis of inhaled foreign body made. Endoscopy was performed under a general anaesthetic, when the trachea and right bronchial tree were found to be normal. A piece of mud was, however, seen in the left lower lobe bronchus. This was crushed and removed piecemeal. When the bronchus was seen to be quite clear the bronchoscope was removed. The child improved rapidly and was returned to the ward. Post-operatively antibiotics were given and postural coughing and breathing exercises started. Radiographs taken a few days later showed re-expansion of the right lower lobe but persistent collapse of the right upper lobe. The child by this time was very well, but in view of the chest film bronchoscopy was repeated some days later. In spite of a careful search, particularly of the right upper lobe, no foreign material could be seen. A bronchogram was performed which showed defective filling of the right upper lobe.

The child still felt well and was discharged to continue postural coughing and breathing exercises.

There are two explanations possible for this collapse of one lung, with the foreign body in the other. The foreign body could have moved to the left side after the initial chest film had been taken, leaving a small piece in the right upper lobe ; but this was not in keeping with the normal endoscopic appearances. Alternatively, the child had a long-standing collapse of the right upper lobe and inhaled a piece of mud into the left bronchus. This would account for the urgent symptoms in this case and their relief by removal of the piece of mud from the previously normal lung. This seems the more likely explanation. We shall keep the child under observation and reassess the right upper lobe later.

CASE 4.-A child was admitted to hospital with a history of having inhaled a date seed four years previously. He stated that he had coughed out the seed after four months. Since that time he had complained of increasing cough and had produced $6 \mathrm{oz}$ of foul-smelling sputum daily. On examination there were moist sounds over the left chest only. Routine sputum tests were normal. A plain radiograph showed cystic changes in the left lower lobe. The right lung was normal. Bronchoscopy was performed under a general anaesthetic and after a careful search no foreign body or other abnormality could be seen. Bronchography showed severe bronchiectasis of the left lung, involving all segments with the exception of the apicoposterior. The right lung was normal and, in view of the severe symptoms, a pneumonectomy was performed from which he made an uneventful recovery. At operation the lung hilum was free of glands. Examination of the specimen revealed no evidence of a foreign body, bronchostenosis, or tuberculosis. There was severe bronchiectasis of the entire lung. The pathologist commented on the absence of inflammatory change. It was assumed that this was a case of bronchiectasis resulting from a foreign body retained for four months. The boy is now symptom-free.

\section{SUMMARY}

Fourteen consecutive cases of inhaled foreign bodies are described.

The importance of the "reliable witness" in the history in children is stressed.

Clinical and radiological confirmatory signs in radio-translucent foreign bodies are commonly absent.

When the foreign body is a peanut, laryngotracheo-bronchitis can be a serious or a fatal complication.

Children under 2 years should be watched carefully in the immediate post-operative period. Tracheotomy is commonly needed and should not be left until too late. The care of the tracheotomy in infants is emphasized.

It is inadvisable to embark on the treatment of these cases without the necessary equipment.

I wish to thank Dr. Ahmed Ali Zaki, Director of the Sudan Medical Service, and Dr. Abdel Halim, Director, Khartoum Civil Hospital, for permission to publish these cases, Dr. S. Bose, M.B., D.A., Senior Lecturer in Anaesthetics, University of Khartoum, who anaesthetized the patients in this series, and Professor H. V. Morgan, M.D., F.R.C.P., Professor of Medicine, University of Khartoum, for his help in the preparation of this paper.

\section{REFERENCES}

Clerf, L. H. (1940). Surg. Gynec. Obstet., 70, 328

Holinger, P. H., and Rigby, R. G. (1946). Med. Clin. N. Amer., 30, 105.

Robinson, C. L. N., and Mushin, W. W. (1956). Brit. med. J., 2, 324 Sauerbruch, F., and O'Shaughnessy, L. (1937). Thoracic Surgery. Arnold, London. 